University of Nebraska - Lincoln

DigitalCommons@University of Nebraska - Lincoln

$3-2008$

\title{
Academic Performance of Students with Emotional and Behavioral Disorders Served in a Self-Contained Setting
}

\author{
Kathleen Lynne Lane \\ Vanderbilt University, kathleen.lane@ku.edu \\ Sally M. Barton-Arwood \\ Belmont University, arwoods@mail.belmont.edu \\ J. Ron Nelson \\ University of Nebraska - Lincoln, rnelson8@unl.edu \\ Joseph Wehby \\ Vanderbilt University, joseph.wehby@vanderbilt.edu
}

Follow this and additional works at: https://digitalcommons.unl.edu/specedfacpub

Part of the Special Education and Teaching Commons

Lane, Kathleen Lynne; Barton-Arwood, Sally M.; Nelson, J. Ron; and Wehby, Joseph, "Academic Performance of Students with Emotional and Behavioral Disorders Served in a Self-Contained Setting" (2008). Special Education and Communication Disorders Faculty Publications. 44.

https://digitalcommons.unl.edu/specedfacpub/44

This Article is brought to you for free and open access by the Department of Special Education and Communication Disorders at DigitalCommons@University of Nebraska - Lincoln. It has been accepted for inclusion in Special Education and Communication Disorders Faculty Publications by an authorized administrator of DigitalCommons@University of Nebraska - Lincoln. 
Published in Journal of Behavioral Education 17:1 (March 2008), pp. 43-62;

doi: 10.1007/s10864-007-9050-1 Copyright ( 2007 Springer Science+Business

Media, Inc. Used by permission.

Submitted April 2, 2007; accepted July 3, 2007; published online August 3, 2007.

\title{
Academic Performance of Students with Emotional and Behavioral Disorders Served in a Self-Contained Setting
}

\author{
Kathleen Lynne Lane \\ Department of Special Education, Peabody College, Vanderbilt University, \\ Box 328, Nashville, TN 37203, USA; email Kathleen.lane@vanderbilt.edu \\ Sally M. Barton-Arwood \\ School of Education, Belmont University, 1900 Belmont Boulevard, \\ Nashville, TN 37212, USA; email arwoods@mail.belmont.edu \\ J. Ron Nelson \\ Special Education and Communication Disorders, University of Nebraska-Lincoln, \\ 247B BKC UNL, Lincoln, NE 68583-0732, USA; email rnelson@unlserve.unl.edu \\ Joseph Wehby \\ Department of Special Education, Peabody College, Vanderbilt University, \\ Box 328, Nashville, TN 37203, USA; email joseph.wehby@vanderbilt.edu
}

\begin{abstract}
This study describes the academic, social, and behavioral performance of elementary and secondary students with emotional and behavioral disorders (EBD) receiving services in a self-contained school for students with serious behavior problems, with an emphasis on how school adjustment and problem behavior patterns predict academic performance. Results revealed that elementary and secondary group scores were well below the 25th percentile on reading, math, and written expression measures. Further, a seven variable model representing academic, social, and behavioral domains was able to differentiate between age groups explaining $54 \%$ of the variance and correctly classifying $78.26 \%(n=18)$ of the elementary students and $84.21 \%(n=16)$ of the secondary students. Findings also suggested that behavioral variables (e.g., school adjustment, externalizing, and internalizing) were predictive of broad reading and broad written expression scores, with school adjustment (a protective factor) accounting for the most variance in the three-variable model. Limitations and recommendations for future research are addressed.
\end{abstract}

Keywords: Academic outcome, Emotional and behavioral disorders 


\section{Introduction}

Students with emotional and behavioral disorders (EBD) commonly engage in behaviors (e.g., verbal and physical aggression; social skills acquisition and performance deficits) that negatively influence both their ability to successfully negotiate peer and adult relationships and their educational experience (Cullinan and Sabornie 2004; Gresham et al. 2004; Landrum et al. 2003; Walker et al. 1992; Walker et al. 2004). Namely, when students are unable to negotiate social demands and meet teachers' expectations for school success (Lane, Givner et al. 2004; Lane, Pierson et al. 2004; Lane et al. 2006), school becomes a formidable task. In the absence of effective interventions, these behavior patterns become more firmly established and less amenable to intervention efforts (Kazdin 1987; Walker et al. 2004).

In recent years, increasing evidence also has established the negative academic outcomes typical of this population. For example, students with EBD earn lower grades, are less likely to pass classes, and experience higher rates of school drop out than typical students and students with other high incidence disabilities (Wagner and Cameto 2004). Despite increased attention to the academic needs of students with EBD, their academic achievement, like their behavioral and social skills, does not appear to be improving (Lane et al. 2002). Unfortunately, these poor outcomes do not improve when they leave the school setting. This group of students goes on to have negative employment outcomes, difficulties with substance abuse, and a high need for mental health services (Bullis and Yovanoff 2006; Walker et al. 2004). Given that between $2 \%$ and $20 \%$ of the school-age population is likely to have EBD, this is no small problem.

\section{Academic Achievement of Students with EBD}

Prevalence rates for students with EBD who have comorbid academic and behavioral challenges vary, ranging from $25 \%$ to $97 \%$ (Reid et al. 2004). The poor academic functioning of students with EBD is not surprising given that academic underachievement is part of the identifying criteria in the federal definition for emotional disturbance (IDEIA 2004; Mooney et al. 2003).

Although the comorbid existence of EBD and academic deficits has been documented over time (Nelson et al. 2004), in recent years, researchers have attempted to elucidate the specific characteristics of the academic performance of students with EBD. Multiple studies suggest that students with EBD perform 12 years below grade level, with significant differences in achievement as compared to students without disabilities (Kauffman 2001; Reid et al. 2004; Trout et al. 2003). In a meta-analysis of the academic status of students with EBD, Reid and colleagues reported a general academic functioning level at the 25th percentile with an overall effective size of -.69 , indicating moderate to large differences in achievement as compared to students without disabilities. In terms of specific areas of academic functioning, students with EBD exhibit broad deficits including underachievement in math, reading, reading comprehension, vocabulary, and written language (Anderson et al. 2001; Coutinho 1986; Greenbaum et al. 1996; Lane et al. 2006; Nelson et al. 2003; Nelson et al. 2004; Trout 
et al. 2003). Further, the limited information available suggests that boys and girls with EBD have comparable academic achievement deficits (Nelson et al.). Thus, relative to their typical peers, boy and girls with EBD have broad academic deficits.

Researchers also have examined how students with EBD progress over time. Unfortunately, the literature consistently indicates that students with comorbid EBD and academic deficits do not improve over time (Anderson et al. 2001; Nelson et al. 2004). However, details on what actually occurs in the academic development of these students are inconsistent. Some studies have indicated that academic deficits remain stable over time (Anderson et al. 2001; Mattison et al. 2002; Reid et al. 2004). For example, in a meta-analysis of the academic performance of students with EBD, Reid and colleagues reported no significant differences between children and adolescents. However, there is evidence indicating that, for some students, academic deficits become worse as they age. For example, in a cross sectional study of 155 students with EBD in grades K-12, Nelson and colleagues reported that while reading and written language levels remained stable (i.e., no significant differences between younger and older students), there were significant differences between children and adolescents in mathematics. This outcome suggests that mathematic deficits may increase as students with EBD get older. In contrast, an earlier study conducted by Coutinho (1986) also suggested declining academic deficits across the content areas as students increased in age. However, these findings should be interpreted very cautiously given Coutinho drew this conclusion based on increases in grade-level equivalent differences across time. Standard scores, which allow for such comparisons over time, were not analyzed. Regardless as to whether academic performance remains stable or declines over time, this lack of improvement is concerning.

Discrepancies in outcomes may be related to several issues. First, as illustrated above, the type of scores analyzed may influence outcomes. Second, the age range in the samples may vary and, consequently, influence outcomes. For example, the mean ages of the students in studies reviewed by Reid et al. (2004) appeared to be from 5.90 to 14.40 years, and the students in the study by Nelson et al. (2004) appeared to be older with mean ages ranging from 6.28 to 18.60. However this explanation should be considered with caution as only partial details regarding students' ages were provided by Reid et al. (2004) (i.e., means were reported in the summary tables, but age ranges were not reported). A third possible explanation could be settings in which studies were conducted. For example in the meta-analysis conducted by Reid and colleagues, students were educated in a variety of settings, ranging from resource programs to separate day schools to clinical outpatient settings. It is possible that progress in academic achievement may vary as a function of setting (Lane et al. 2005a).

Academic Achievement of Students with EBD Educated in Self-contained Settings

Although the long-term outcomes for academic achievement in students with EBD are not promising, presumably, one would expect better progress-behaviorally, 
socially, and academically - in settings customized to meet their multiple needs (Lane et al. 2005a). For example, one may reason that self-contained classrooms or self-contained schools are better equipped with the resources and services these students require. Specialized educational environments have the perceived benefit of smaller class sizes, paraprofessional support (Singer et al. 1986), modified curriculum, varied instructional strategies (Meadows et al. 1994), and stronger classroom management (Kauffman and Wong 1991). These extensive supports should result in better academic and social progress relative to other placements (e.g., general education setting) that do not allow for the same level of individualization (Lane et al. 2005a). However, the existing, yet limited data suggests otherwise.

In their meta-analysis, Reid et al. (2004) reported that across all placements (i.e., general education, resource, self-contained and special school placement), students with EBD continued to exhibit significant academic delays. In two studies conducted after Reid and colleagues' review, Lane et al. (2005a, b) compared the academic profiles of students with EBD in self-contained classrooms and selfcontained schools. They found that although students in both settings demonstrated broad academic deficits, students in self-contained schools had lower academic achievement than students in self-contained classrooms. Further, their research revealed that students made limited academic progress in either setting on reading and math skills. This lack of academic progress may be due to a number of factors including (a) the greater emphasis on behavioral programming and social skills instruction relative to academic instruction (Lane et al. 2005a, b; Mooney et al. 2003; Reid et al. 2004), (b) outcomes measures that may not be sensitive to change (Lane 1999), or (c) the presences of other variables (e.g., hyperactivity, externalizing, internalizing behaviors) that may influence students' academic progress Reid et al. (2004).

\section{Relationship Between Types of Problem Behaviors and Academic Achievement}

In recent years, researchers have examined the relation between various subtypes of EBD and academic performance. For example, Mattison et al. (1998) reported a relation between conduct and oppositional problems (Diagnostic and Statistical Manual of Mental Disorders-III, American Psychological Association [APA], 1994) and academic achievement in a convenience sample of elementary and secondary age students with EBD. More specifically, the presence of a DSM-III Conduct or Oppositional Defiant Disorder, increasing enrollment age, a verbal intelligence quotient (IQ) significantly lower than performance IQ, and the absence of any DSM-III anxiety or depressive disorders were significant predictors of unsuccessful academic outcomes. Similarly, Abikoff et al. (2002) found that the co-occurrence of Disruptive Behavior Disorders and Attention Deficit/Hyperactivity Disorder was more indicative of academic achievement deficits relative to other psychiatric disorders present in isolation or combination. Finally, Nelson et al. (2004) conducted a cross sectional study of academic achievement of $155 \mathrm{~K}-12$ students with EBD receiving special education services to examine how particular types of problem behaviors (internalizing and externalizing) related to academic performance. Findings revealed that externalizing, and not internalizing, behaviors were associated with academic performance in reading, mathematics, 
and writing. These results also were consistent with previous studies that indicated a relation between academic underachievement and problems of conduct and attention (Lane et al. 2001; Mattison et al. 1998).

\section{Purpose}

In the present study we sought to confirm and extend the current knowledge base of academic characteristics of students with EBD, with a focus on students receiving special education services in a self-contained school dedicated to service delivery for students with EBD. However, in this study we incorporated different social and achievement measures to assess performance. Whereas most studies examining the relation between academic achievement and behavior based on dimensional measures is restricted to the Teacher Report Form (TRF; Achenbach 1991) and standardized measures of reading achievement, this study used different social and achievement measures. Specifically, we used the Social Skills Rating System (SSRS; Gresham and Elliott 1990) to assess externalizing and internalizing behaviors and the Walker-McConnell Scale of Social Competence and School Adjustment (Walker and McConnell 1995) to assess overall school adjustment, a protective behavioral characteristic absent in previous investigations. These measures were selected as they have been viewed by teachers as less cumbersome to complete relative to the TRF (Lane et al. 2007). Further, we used curriculum-based measures to accompany standardized measures of achievement with a goal of (a) including measures that were sensitive to change and (b) addressing the recommendation of multioperationalism - that is using varied measures of the construct of interest (Gresham et al. 2000).

In addition, although there are data to suggest that the academic and behavioral performance of students with EBD declines over time (Greenbaum et al. 1996; Nelson et al. 2004; Walker et al. 2004), there is little information regarding variables that predict differences in elementary and secondary students' achievement. Better understanding behavioral characteristics that may predict differences between grade levels has the potential to inform intervention efforts. For example, if we find that externalizing behaviors are more predictive of the academic performance of elementary age students, rather than secondary age students, this information could be used to identify students with externalizing behaviors at the earliest possible juncture to provide focused intervention support to prevent the development of academic deficits.

In the present study, we examined mean levels of performance of elementary and secondary students and computed effect sizes to determine the magnitude of differences in performance patterns between these two groups of students. Then, we conducted descriptive and predictive discriminant function analyses to determine the degree to which the behavioral, social, and academic variables identified as revealing high-magnitude differences $\left(\mathrm{ES}_{\mathrm{sm}}\right.$ greater than 1.00) could discriminate between elementary and secondary groups. Finally, multiple regression procedures were employed to ascertain the extent to which externalizing behaviors, internalizing behaviors, and school adjustment predicted academic performance. Based on the findings of earlier investigations, we hypothesized the following results: (a) students would demonstrate lower than average academic, social, and 
behavioral skill sets, with the adolescent group exhibiting more severe deficits; (b) academic, social, and behavioral skills would be significantly predictive of group membership; and (c) school adjustment and externalizing variables would be more predictive of academic performance than internalizing behaviors, with school adjustment being most predictive.

\section{Method}

\section{Participants}

Participants were 42 students, primarily with emotional disturbance, educated in a self-contained school dedicated to serving students with significant emotional and behavioral disorders (EBD). The school was located in a southern metropolitan public school district. All students were originally educated in the general education setting followed by placement in a self-contained classroom in a general education campus due to serious behavior challenges. Placement in the self-contained school occurred when a multidisciplinary team determined that behavioral problems (e.g., verbal and physical aggression; noncompliance) exceeded normative criteria to the extent that students could not benefit from services in the more inclusive settings (Lane et al. 2005a, b). Although educated on the same campus, 23 students were elementary age (kindergarten through fifth grade; $82.61 \%$ male) and 19 were secondary age (sixth through eighth grade; $78.95 \%$ male; see Table 1$)$. Thirty-four students $(80.95 \%)$ were male with all students ranging in age from 7.01 to 14.03 years $(M=10.87, S D=1.87)$. Thirty-three $(78.57 \%)$ students were African American, 8 (19.05\%) were Caucasian, and 1 (2.38\%) was Hispanic. With respect to primary disability, 31 (73.81\%) students had a classification label of emotional disturbance (ED) per the Individuals with Disabilities Education Improvement Act (IDEIA, 2004), 5 (11.90\%) other health impaired - Attention Deficit Hyperactivity Disorder (ADHD; APA, 1994), 3(7.14\%) learning disability (LD), $1(2.38 \%)$ speech and language impairment, and 2 (4.76) mental retardation. The range of primary disability categories reported for this sample is comparable to other studies conducted in this setting, and all students had serious behavioral challenges that warranted support in a self-contained school for students with EBD (e.g., Barton-Arwood et al. 2005; Lane et al. 2005a; Mooney et al. 2003; Reid et al. 2004; Sutherland and Wehby 2001; Wehby, Falk et al. 2003; Wehby, Lane et al. 2003).

Intelligence data were retrieved from the students' cumulative files. There was no significant difference between elementary and secondary students with respect to intellectual performance, $t(40)=.72, p=.47$, assessed using a school psychologist-administered intelligence test (e.g., Wechsler Intelligence Scale for ChildrenThird Edition [WISC-III; Wechsler 1991]). A chi-square analysis contrasting grade level groups (elementary vs. secondary) $\times$ gender $\left[\chi^{2}(1, N=42)=.09, p=.76\right]$ was not significant. Chi-square analyses involving ethnicity and primary classification label were not possible due to low cell counts. 







\section{Procedures}

All nine teachers at a single self-contained school in middle Tennessee participated in this investigation by (a) completing the Social Skills Rating System (SSRS, Gresham and Elliott 1990) and Walker-McConnell Scale of Teacher and Peer Preferred Social Behavior and School Adjustment (Walker and McConnell 1995); (b) administering curriculum-based measures of oral reading fluency and reading comprehension (Boning 1998) to participants; and (c) allowing research assistants to complete school record reviews using the School Archival Record Search (SARS; Walker et al. 1991). This school was selected for participation in this study as it was the only self-contained school in this southern metropolitan public school district exclusively dedicated to serving students with EBD. Of the 60 enrolled students, parental consent and student assent was obtained for $42(70 \%)$. Thus, all students enrolled in the school were eligible for participation in the study; there were no exclusionary criteria. Data were not collected for nonconsented students. Consequently, it was not possible to conduct statistical analyses comparing consented and nonconsented students. However, informal information provided by the school-site personnel suggested that there were no obvious differences between the students who did and did not participate in this study.

All teachers were required to teach the district's core curriculum and address the district standards, which operationalized instructional objectives for reading, math, social studies, and science content areas. The self-contained school had a strictly-implemented point system as part of its school wide discipline plan. Students evaluated three school goals (follow directions, keep body under control, and be nice to others) as well as one personal goal (identified by the multidisciplinary team) at 11 time points over the instructional day. Each classroom was staffed with a state certified special education teacher, instructional aide, and mental health counselor. The teacher was responsible for serving as the instructional leader by preparing and conducting daily lessons. The instructional aide provided both instructional and behavioral support to the students. The mental health counselor provided behavioral support in the classroom and conducted group therapy sessions with the students once a week. In addition, the school employed additional staff to assist with implementing exclusionary time-out procedures for students exhibiting severe behavioral problem which could result in being placed in an exclusionary time-out area (if such procedures were specified in the students' individualized educational program).

\section{Measures}

Measures included a variety of psychometrically-sound instruments and procedures which were administered during the onset of the academic year. Academic performance levels were assessed using the Woodcock-Johnson III Test of Achievement (WJ-III; Woodcock et al. 2001), curriculum-based measures (Boning 1998) of oral reading fluency and reading comprehension, and the academic competence scales of the Social Skills Rating System (SSRS). Social and behavioral performance levels were assessed using two teacher-completed behavior rating scales, the So- 
cial Skills Rating System (SSRS) and the Walker-McConnell Scale of Social Competence and School Adjustment (SCSA), and research assistant-completed school record review using the School Archival Record Search (SARS; Walker et al. 1991). In selecting specific instruments and variables to be analyzed, we included those that (a) were typically used by schools in monitoring student progress and making placement decisions and (b) reflected common characteristics of students with EBD. These selection guidelines have been utilized in other descriptive studies of students with EBD (Lane et al. 2005a, 2005b).

\section{Woodcock-Johnson III Test of Achievement (WJ-III)}

The WJ-III is an individually-administered achievement battery. Results may be used to assist in diagnosing learning disabilities, designing educational and individual programs, conducting research, providing direction in educational and clinical settings, and assessing academic growth. The WJ-III contains two parallel forms (A and B) with two batteries: Standard and Extended. The WJIII Standard Battery yields 10 cluster scores, three of which were examined in this study: broad reading (READ), broad math (MATH), and broad written language (WRITE), with reliability estimates of .90 and higher. Broad reading is comprised of letter-word identification, reading fluency, and passage comprehension subtests. Broad math is comprised of calculation, math fluency, and applied problems subtests. Broad written language is comprised of spelling, writing fluency, and writing samples. Administration time for the Standard Battery of 11 tests is approximately 55-65 min. In this study, the WJ-III Standard Battery was administered by the classroom teachers. The accompanying computerized scoring system was used to ensure scoring accuracy. Percentile scores were used to compare groups.

\section{Curriculum-based Measures: Oral Reading Fluency and Reading Comprehension}

Grade level passages from Boning's (1998) Multiple Skills Series: Reading were administered individually to assess oral reading fluency (ORF) and reading comprehension skills (RCMP). To assess ORF, each student was asked to read the grade level passage aloud while teachers coded the number of words read correctly and incorrect responses (omissions, substitutions, hesitations, and mispronunciations). To measure RCMP, students silently read a separate grade-level passage and completed five multiple-choice questions. The percentage of correct responses was determined by dividing the number of correct responses by the total number of questions. ORF and RCMP probes were administered bi-weekly over the course of the academic year. For this study, the first two probes were averaged together. Teachers and research assistants participated in approximately 6 hours of training and reached .90 reliability before administering probes. Research assistants monitored reliability for $25 \%$ of the ORF and RCMP probes simultaneously with mean inter-rater reliability estimates of 98.2\% $(S D=4.9)$ and $100 \%$ for ORF and RCMP, respectively. Two RAs were presented during the actual administration to assess inter-rater reliability. 


\section{Social Skills Rating System-Teacher Version (SSRS-T)}

Teachers completed the SSRS-T at the onset of the year to assess social skills, problem behaviors, and academic competence. The social skills subscale contains 30 items constituting 3 factor analytically-derived domains: cooperation, assertion, and self-control. Each item is rated on two 3-point Likert-type scales to assess the frequency (never $=0$, sometimes $=1$, to very often $=2$ ) and importance (not important $=0$, important $=1$, to critical $=2$ ) of each item. Teachers also rate behavioral items on the frequency scale to assess problem behaviors. The elementary version contains 18 behavior problems that constitute three domains (externalizing [EXT], internalizing [INT], and hyperactivity [HYP]); whereas the secondary versions contains 12 behavior problems that constitute two domains (externalizing and internalizing). The elementary and secondary versions contain 9 academic competence items rated by teachers on a 5-point Likert-type scale with each point corresponding to clusters (lowest 10\% $=1$ to highest 10\% =5). Coefficient alpha reliabilities range from .78 to .95 .

\section{Walker McConnell Scale of Social Competence and School Adjustment (SCSA)}

The elementary version of the SCSA contains 3 factor-analytically-derived subscales: peer-related adjustment (17 items), teacher-related adjustment (16 items), and school adjustment (10 items). The secondary version contains four subscales, self-control (13 items), peer relations (16 items), school adjustment (15 items), and empathy (15 items). Each item is rated on a 5-point Likert-type scale ranging from never occurs (1) to frequently occurs (5). For this study, elementary and secondary students were compared on school adjustment (ADJUST). Alpha coefficients range from .89 to .98 . Teachers completed this measure at the onset of the school year.

\section{School Archival Record Search (SARS)}

The SARS quantifies school records data on 11 dimensions: demographics, attendance, achievement test information, school failure, disciplinary contacts, within-school referrals, special education eligibility, placement, Chapter I services, out-of-school referrals, and negative narrative comments. In this study, absences, negative narrative comments, and disciplinary contacts were utilized. Absences refers to the total number of days the student was not in attendance during the academic year. A score of greater than 10 is considered a negative risk factor. Negative narrative comments refers to the total number of negatively worded items written in the cumulative folder (e.g., Jon hit another student.) over the course of the academic year. Disciplinary contacts refers to the total number of rule violations that resulted in a contact with the school site disciplinarian. Interrater reliability estimates range from $94 \%$ to $100 \%$ with a total form estimate of $96 \%$. Research assistants completed a 6 hour training program before collecting data. 


\section{Experimental design}

First, this study employed a causal-comparative design to determine the extent to which (a) academic, social, and behavioral variables could discriminate between elementary and secondary students with EBD and (b) behavioral and social characteristics could predict academic performance. Variables that reflected typical characteristics of students with EBD (e.g., internalizing and externalizing behaviors) as well as those that were typically used by multidisciplinary teams (e.g., disciplinary contacts) in making placement decisions were included in the data analysis process. Below we discuss the statistical analyses conducted for each objective, providing an explanation and justification for the specific procedures employed.

\section{Results}

Differentiating Performance of Elementary and Secondary Students

\section{Statistical Analysis}

Elementary and secondary students were contrasted on 12 variables by computing effect sizes to determine the magnitude of the differences between groups. Effect sizes $\left(\mathrm{ES}_{\mathrm{sm}}\right)$ were computed using the pooled standard deviation as well as the correlation between the two subgroups in the denominator (Lipsey and Wilson 2001; see Table 2).

Table 2. Group means for variables by domains

\begin{tabular}{|c|c|c|c|c|}
\hline \multirow[t]{3}{*}{ Performance area } & \multirow[t]{3}{*}{ Variable } & \multicolumn{2}{|c|}{ Grade level } & \multirow{3}{*}{ Effect size } \\
\hline & & \multirow{2}{*}{$\begin{array}{c}\text { Elementary }(n=23) \\
M(S D)\end{array}$} & \multirow{2}{*}{$\begin{array}{c}\text { Secondary }(n=19) \\
M(S D)\end{array}$} & \\
\hline & & & & \\
\hline \multirow[t]{6}{*}{ Academic } & Broad reading & $10.83(16.56)$ & $14.57(17.66)$ & .01 \\
\hline & Broad math & $22.34(18.71)$ & $13.25(13.60)$ & -2.23 \\
\hline & Broad written expression & $15.02(15.27)$ & $15.28(20.60)$ & .06 \\
\hline & Oral reading fluency & $43.67^{*}(36.21)$ & $72.82 *(45.02)$ & 4.59 \\
\hline & Reading comprehension & $61.11(21.30)$ & $55.63(25.16)$ & -1.14 \\
\hline & Academic competence & $30.09(25.02)$ & $36.27(23.41)$ & 1.28 \\
\hline \multirow[t]{2}{*}{ Social } & School adjustment & 30.17 (23.27) & $35.72(14.49)$ & 1.25 \\
\hline & Social skills & $31.04(22.41)$ & $30.87(25.38)$ & -.03 \\
\hline \multirow[t]{4}{*}{ Behavioral } & Problem behavior & $86.00(10.47)$ & $90.40(7.18)$ & 1.46 \\
\hline & Absences & $5.19 *(5.01)$ & $12.76^{*}(9.87)$ & 2.75 \\
\hline & Negative narrative comments & $32.05(35.20)$ & $33.12(25.10)$ & .19 \\
\hline & Disciplinary contact & $14.14(27.79)$ & $17.76(11.18)$ & .77 \\
\hline
\end{tabular}

Means with an asterisk indicate a significant differences, $p<0.05$. The effect size of zero is due to a score of zero in the numerator. Ethnicity datum was not available for one student. 
Next, descriptive and predictive discriminant function analyses were computed to determine the degree to which significant variables with high-magnitude effect sizes $\left(\mathrm{ES}_{\mathrm{sm}}\right.$ greater than 1.00) could discriminate group membership (elementary vs. secondary). The predictive discriminant function analyses using variables from the descriptive discriminant function as classification variables was computed to ascertain classification rates, with group membership as the criterion variable. Although the sample size was small, we met the minimum sample size to support the number of variables in the model (Klienbaum et al. 1998).

\section{Findings}

Results of effect sizes calculations identified seven variables with high-magnitude effect between elementary and secondary students: four academic, one social, and two behavior. Academic variables included broad math $\left(\mathrm{ES}_{\mathrm{sm}}=-2.23\right)$, oral reading fluency $\left(\mathrm{ES}_{\mathrm{sm}}=4.59\right)$, reading comprehension $\left(\mathrm{ES}_{\mathrm{sm}}=-1.14\right)$, and academic competence $\left(\mathrm{ES}_{\mathrm{sm}}=1.28\right)$. School adjustment was the only variable from the social domain yielding a high-magnitude difference between groups ( $\left.\mathrm{ES}_{\mathrm{sm}}=1.25\right)$. Behavioral variables included problem behavior $\left(\mathrm{ES}_{\mathrm{sm}}=1.46\right)$ and absences $\left(E S_{s m}=2.75\right)$. In brief, elementary students had higher performance in broad math and reading comprehension scores as well as lower levels of absenteeism than secondary students. Secondary students had higher oral reading fluency, academic competence, and school adjustment scores than elementary students. Secondary students also had higher problem behavior scores compared to elementary students. A descriptive discriminant function analysis was computed using the variables with high-magnitude effect sizes. Specifically, grade level (elementary vs. secondary) served as the criterion variable and broad math, oral reading fluency, reading comprehension, academic competence, school adjustment, problem behavior, and absences as predictor variables.

\section{Findings}

The 7 variable model explained $54 \%$ of the variance, $F(7,34)=5.67, p<.0002$, Wilks' lambda $=.46$. Findings of a cross-validated classification analysis (prior probabilities of .50$)$ resulted in $78.26 \%(n=18)$ of the elementary students and $84.21 \%(n=16)$ of the secondary students correctly classified. The total error count estimate was $18.76 \%(n=8)$.

Behavioral and social characteristics predicting academic performance

\section{Statistical Analysis}

Multiple regression procedures were used to determine the degree to which behavioral and social characteristics predicted academic performance. Specifically, results were obtained using bivariate correlation and multiple regression procedures. Multiple regression procedures examining externalizing behaviors (EXT), 
internalizing behaviors (INT), and school adjustment (ADJUST) predicted five outcome variables: broad reading, broad math, broad written expression, oral reading fluency, and reading comprehension. If the overall model was significant, as determined by the $F$-value, then univariate analyses were conducted to determine the unique contribution each of the three variables in the model. T-tests were examined to determine the significant, unique contribution of each predictor variable, controlling for the remaining five variables. Standardized multiple regression coefficients (also referred to as beta weights), and uniqueness indices were examined to identify the relative value of each predictor variable constituting the model. The unique index for a given predictor is the percentage of variance in the criterion variable accounted for by that predictor variable after taking into consideration the variance explained by the remaining predictor model. Semipartial correlations determine the relationship between the predictor and criterion variable, controlling for the other variables in the model (see Table 3), where as bivariate correlations examined overall relationships,

$$
\mathrm{Y}=\beta_{0}+\beta_{\mathrm{EXT}}+\beta_{\mathrm{INT}}+\beta_{\mathrm{ADJUST}}+\varepsilon
$$

This model was constructed based on the hypothesis that students with higher levels of externalizing and internalizing behaviors and lower levels of school adjustment would exhibit lower levels of academic competencies, particularly in literacy skills. The main assumptions underlying multiple regression analyses (e.g., independent observations, measurement error, and specification errors) were met, thereby justifying the appropriateness of this method of data analysis. Further, Cohen (1992) indicates that only 34 participants are required to obtain significance (alpha $=.05)$ in detecting a large effect size with a multiple regression model containing 3 predictor variables.

\section{Findings}

Of the five models tested, only two were significant: READ and WRITE. Models predicting curriculum-based variables (oral reading fluency and reading comprehension) and math were not significant. The three variable model accounted for $27 \%$ of the variance in students' broad reading (READ) scores, $R^{2}=.27, F(3$, $38)=4.77, p=.007$. Inspection of semipartial correlations indicated that two variables, school adjustment (ADJUST), $t=2.25, p=.03$, and internalizing behavior (INT), $t=2.22, p=.033$, were significant in predicting READ scores, accounting for $9.72 \%$ and $9.42 \%$ of the variance in READ, respectively, after controlling for the other variables in the model. Students with higher levels of school adjustment and internalizing behaviors had higher READ scores (see Table 3).

The three variable model accounted for $21 \%$ of the variance in students' broad written expression skills (WRITE) scores, $R^{2}=.21, F(3,38)=3.37, p=.028$. Inspection of semipartial correlations indicated that only one variable, school adjustment (ADJUST), $t=2.75, p=.009$, was significant in predicting WRITE scores, accounting for $15.73 \%$ of the variance in WRITE after controlling for the other two variables in the model. Students with higher levels of school adjustment had higher WRITE scores. 


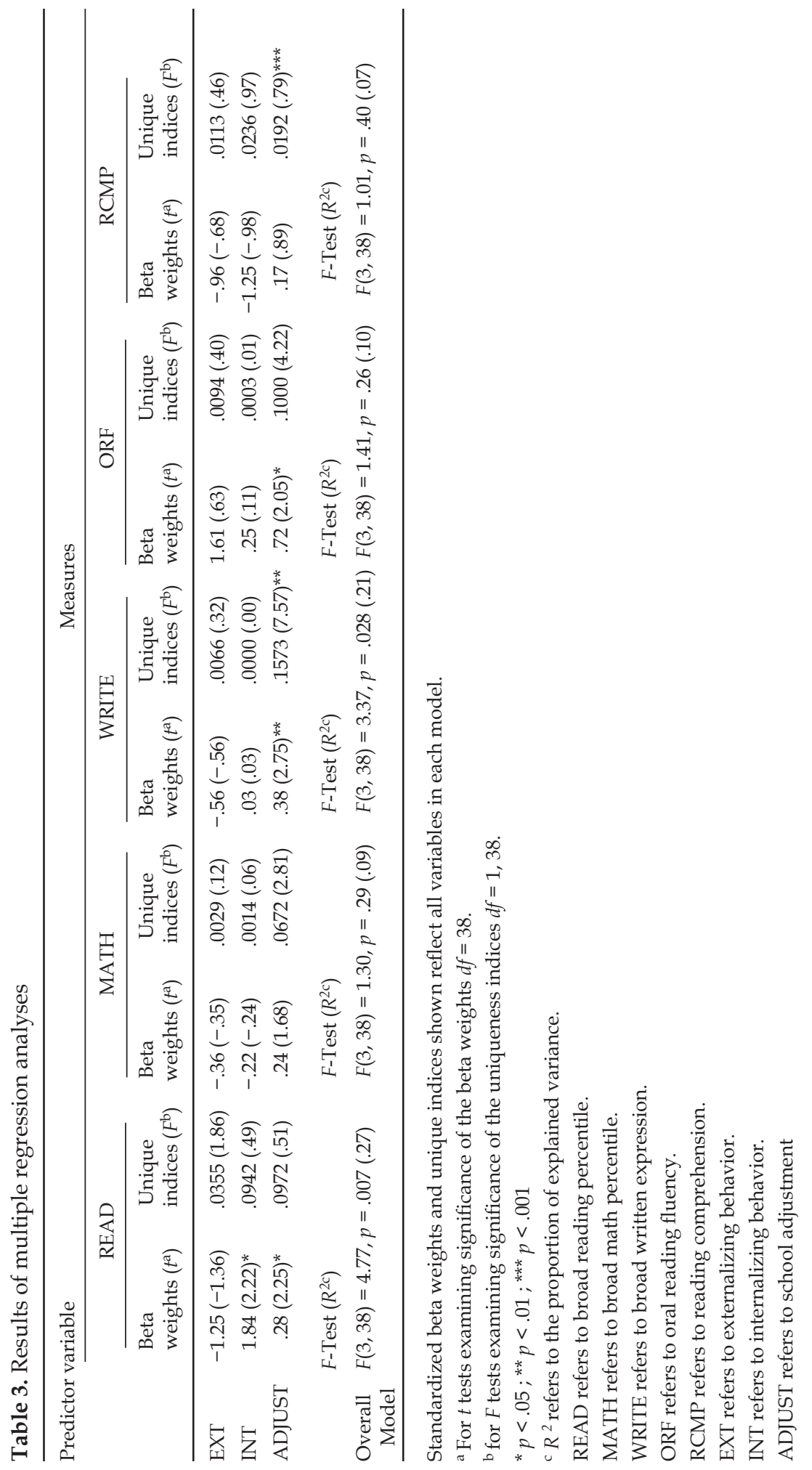




\section{Discussion}

This study examined the academic, social, and behavioral performance of elementary and secondary students with EBD and behavior problems receiving services in a self-contained school for this population. Results were consistent with earlier investigations reporting subaverage academic performance among this group (Greenbaum et al. 1996; Lane et al. 2005a, b; Mooney et al. 2003; Nelson et al. 2004; Reid et al. 2004; Trout et al. 2003). Elementary and secondary group scores were well below the 25th percentile for reading, math, and written expression measures, with high magnitude differences $\left(\mathrm{ES}_{\mathrm{sm}}=-2.23\right)$ between the two groups on math performance. The secondary group demonstrated lower skill sets in mathematics. Whereas earlier investigations focused primarily on standardized achievement test, this investigation also used curriculumbased measures to assess academic performance. This is an important extension with practical implications as curriculum-based measures (a) may be sensitive to change, and (b) can be administered more frequently by teachers to inform instructional practices. As expected, orally reading fluency rates were higher for older students, yet reading comprehension skills declined for students in the upper grades. Thus, although students are reading more fluently in the later years, their comprehension skills are not improving commensurately. This is unfortunate given that as students leave the early elementary years, their reading tasks shift from reading-to-read to reading-to-learn (Biancarosa and Snow 2004). Difficulties in reading comprehension will make it particularly difficult for middle and high school students to acquire knowledge from text-a necessary skills for school success (Bhat et al. 2003).

Similarly, social and behavior data confirm earlier research, with teachers reporting (a) below average social skills and school adjustment with mean scores falling in the 30th to 35th percentile range and (b) above average problem behaviors, with high magnitude $\left(\mathrm{ES}_{\mathrm{sm}}=1.46\right)$ difference between elementary and secondary groups. School record data paralleled these findings revealing problems with attendance and behavioral performance while in school. Specifically, absenteeism was significantly higher for the secondary group, with mean absences falling into the at risk category (10 or more absences per year) according to SARS normative criteria (Walker et al. 1991). Similarly, negative narrative comments and disciplinary contacts also exceeded normative levels of $2+$ and $3+$, respectively, with consistent patterns of responding across the grade levels. These findings are consistent with other descriptive studies of academic, social, and behavioral profiles of students with EBD (Nelson et al. 2004; Lane et al. 2005a, b), yet run contrary to finding of Mattison and colleagues that report modest academic deficits for this population (Mattison et al. 1998, 2002). Further, findings from this study suggest that approximately $78 \%$ of elementary students and $84 \%$ of secondary students, could be correctly classified using academic (broad math, orally reading fluency, reading comprehension, and academic competence), social (school adjustment), and behavioral (problem behavior and absences) variables that posited high-magnitude difference between groups. These variables also have been useful in differentiating between different types of behavioral concerns (e.g., internalizing vs. externalizing) in earlier investigations of behavioral, social, and academic profiles of students at risk for 
school failure (Gresham et al. 1999; Gresham et al. 2000) and antisocial behavior (Gresham et al. 2001).

Finally, this study sought to extend the work of Nelson et al. (2004) by examining the degree to which risk (externalizing and internalizing behavior patterns) and protective (school adjustment) factors predicted academic performance. Based on the outcomes of Nelson's work, we hypothesized that externalizing behaviors, and not internalizing behaviors, would be more indicative of academic performance. Further, we also hypothesized that students who more successfully negotiate the behavioral demands of the schools setting, as measures by school adjustment scores, would perform better academically (Kerr and Zigmond 1986; Lane, Givner, et al. 2004; Lane, Pierson et al. 2004; Lane et al. 2006; Walker and Rankin 1983). Yet, our findings only partially confirmed our hypotheses. Of the models tested, these behavioral variables (school adjustment, externalizing, and internalizing) were only predictive of broad reading and broad written expression scores; curriculumbased based reading measures and math scores did not yield a significant prediction. Inspection of semipartial correlations indicated a significant amount of unique variance of reading scores was explained by school adjustment and internalizing scores. Namely, students with higher levels of school adjustment and internalizing behavior patterns performed better in writing. Similarly, school adjustment scores also explained a substantial portion of the unique variance in predicting writing scores. Based on the unique contributions of these three variables, it may be that school adjustment is more predictive of performance on literacy variables, than the presence of externalizing behavior patterns as suggested previously.

Although replication is necessary to establish the generalizability of these findings, there are very practical implications from these outcomes. If overall school adjustment is predictive of academic performance, then intervention efforts should be employed to improve students' overall school adjustment to promote academic success. Namely, by providing more focused intervention efforts that target skills constituting the overall school adjustment domain (e.g., attends to assigned task, has good work habits, listens when others are speaking, cooperates with peers, controls temper, copes effectively), we can develop the skill sets that are predictive of academic performance. It is particularly important to provide explicit instruction for students with EBD in the skills sets constituting school adjustment since students with EBD shift educational settings with high frequency, more so than most other disability categories. As we know from the work of Walker et al. (1991), attending multiple schools (e.g., more than 2 elementary schools or more than 1 middle school) is a risk factor predictive of negative outcomes. Consequently, it is particularly unfortunate that students with EBDwho struggle behaviorally, socially, and academically - are confronted with multiple placement changes forcing them to meet the varied behavioral expectations in these different settings.

\section{Limitations and future directions}

The above results should be interpreted in light of the following limitations: sample size, generalizability of findings; measurement tools selected; and heterogeneity of primary labels. In this study, the sample size was small, particularly for secondary age students. Therefore, it is imperative that results be interpreted con- 
servatively. A small sample size (a) restricts statistical power making it difficult to identify significant differences when comparisons are made (e.g., differences between elementary and secondary students), (b) restricts generalizability of the findings - in short, external validity; and (c) narrows the scope of statistical analyses procedures permitted (e.g., hierarchical linear modeling). Yet, when studying populations with low incidence rates, such as students receiving services for severe behavior problem in a self-contained school, small samples are likely (Lane et al. 2005a, b). One suggestion for future research is to consider include additional schools, across a wider geographic area, to increase sample size, thereby increasing statistical power to detect meaningful difference and enhance external validity.

A second issue pertains to the measurement of social and behavioral performance. Consistent with other investigations (Lane et al. 2005a, b; Mattison et al. 1998), social skills and behavioral patterns were assessed via teacher ratings and school record reviews; direct observations were not conducted. Future inquiries may wish conduct more direct measures to corroborate data gleaned via teacher perceptions. For example, studies using other measures of social behavior such as sociometric ratings (Gresham et al. 1999) or direct observation data (e.g., Lane 1999) may be more sensitive to change and more reflective of actual student-student interaction patterns.

A final limitation is the heterogeneity of the sample. Namely, although the multidisciplinary teams determined that the students demonstrated behavior patterns severe enough to warrant placement in a self-contained school for students with EBD, not all students had ED (IDEIA 2004) as primary label. Future studies are needed to compare the academic, social, and behavioral characteristics of students receiving services under the ED category specified in IDEIA (2004) with the more characteristics of students identified as having EBD but who are not receiving special education services under the ED category (Lane 2004).

\section{Summary}

Despite the limitations noted above, findings from this study confirm earlier works that report substandard performance in academic, social, and behavioral domains; with patterns that remain stable (Anderson et al. 2001; Nelson et al. 2004) or even worsen (e.g., math, Nelson et al. 2004) over time (Kazdin 1987; Walker et al. 2004). Although results, particularly the findings related to the predictive utility of school adjustment, should be considered tentative at best, these outcomes do offer important considerations for educational programming. As stated at the onset of this paper, school adjustment refers to one's ability to negotiate successfully the academic, social, and behavioral demands of the school setting (Walker et al. 1992; Walker and Severson 2002). If these findings are replicated in subsequent studies with larger sample sizes indicating that school adjustment is predictive of reading and writing performance, then intervention efforts aimed at improving school adjustment should be employed. More specifically, if confirmed, findings provide further credence for the importance of intervention efforts such as positive behaviors supports that focusing on improving all students' overall school adjustment by clarifying behavioral expectations and then providing students with opportunities to practice and receive reinforcement for demonstrating these skills. 


\section{References}

Abikoff, H. B., Jensen, P. S., Arnold, L. I., Hoza, B., Hechtman, I., Pollack, I., et al. (2002). Observed classroom behavior of children with ADHD: Relationship to gender and comorbidity. Journal of Abnormal Child Psychology, 30, 349-359.

Achenbach, T. M. (1991). Manual for the child behavior checklist/4-18 and 1991 profile. Burlington: University of Vermont, Department of Psychiatry.

American Psychological Association (1994). Diagnostic and statistical manual of mental disorders (4th ed.). Washington, DC: American Psychiatric Association.

Anderson, J. A., Kutash, K., \& Duchnowski, A. J. (2001). A comparison of the academic progress of students with EBD and students with LD. Journal of Emotional and Behavioral Disorders, 9, 106-115.

Barton-Arwood, S. M., Wehby, J. H., \& Falk, K. B. (2005). Reading instruction for elementary-age students with emotional and behavioral disorders: Academic and behavioral outcomes. Exceptional Children, 72, 7-27.

Bhat, P., Griffin, C. C., \& Sindelar, P. T. (2003). Phonological awareness instruction for middle school students with learning disabilities. Learning Disabilities Quarterly, 26, 73-87.

Biancarosa, G., \& Snow, C. (2004). Reading Next-A vision for action and research in middle and high school literacy. New York: Carnegie Corporation of New York.

Boning, R. (1998). Multiple skills series. Baldwin, NY: Lowell \& Lynwood.

Bullis, M., \& Yovanoff, P. (2006). Idle hands: Community employment experiences of formerly incarcerated youth. Journal of Emotional and Behavioral Disorders, 14, 71-85.

Cohen, J. (1992). A power primer. Psychological Bulletin, 112, 155-159.

Coutinho, M. J. (1986). Reading achievement of students identified as behaviorally disordered at the secondary level. Behavioral Disorders, 11, 200-207.

Cullinan, D., \& Sabornie, E. J. (2004). Characteristics of emotional disturbance in middle and high school students. Journal of Emotional and Behavioral Disorders, 12, 157-167.

Greenbaum, P. E., Dedrick, R. F., Friedman, R. M., Kutash, K., Brown, E. C., Lardierh, S. P., \& Pugh, A. M. (1996). National Adolescent and Child Treatment Study (NACTS): Outcomes for children with serious emotional and behavioral disturbance. Journal of Emotional and Behavioral Disorders, 4, 130-146.

Gresham, F. M., Cook, C. R., Crews, S. D., \& Kern, L. (2004). Social skills training for children and youth with emotional and behavioral disorders: Validity considerations and future directions. Behavioral Disorders, 30, 32-46.

Gresham, F. M., \& Elliott, S. N. (1990). Social skills rating system. Circle Pines, MN: American Guidance Service.

Gresham, F. M., Lane, K. L., \& Lambros, K. (2000). Comorbidity of conduct and attention deficit hyperactivity problems: Issues of identification and intervention with "fledgling psychopaths". Journal of Emotional and Behavioral Disorders, 8, 83-93.

Gresham, F. M., Lane, K. L., MacMillan, D. L., \& Bocian, K. M. (1999). Social and academic profiles of externalizing and internalizing groups: Risk factors for emotional and behavioral disorders. Behavioral Disorders, 24, 231-245.

Gresham, F. M., Lane, K. L., MacMillan, D. L., Bocian, K. M., \& Ward, S. L. (2000). Positive and negative illusory biases: Comparisons across social and academic self-concept domains. Journal of School Psychology, 38, 151-175.

Gresham, F. M., Lane, K. L., McIntyre, L. L., Olson-Tinker, H., Dolstra, L., MacMillan, D., Lambros, K., \& Bocian, K. (2001). Risk factors associated with the co-occurrence of hyperactivity-impulsivity-inattention and conduct problems. Behavioral Disorders, 26, 189-199.

Individuals with Disabilities Education Improvement Act of 2004, 20 U.S.C. 1400 et esq. (2004 (reauthorization of Individuals with Disabilities Act 1990).

Kauffman, J. M. (2001). Characteristics of emotional and behavioral disorders of children and youth (7th ed.). Columbus, OH: Merrill. 
Kauffman, J. M., \& Wong, K. L. H. (1991). Effective teachers of students with behavioral disorders: Are generic teaching skills enough? Behavioral Disorders, 16, 225-237.

Kazdin, A. (1987). Treatment of antisocial behavior in children: Current status and future directions. Psychological Bulletin, 102, 187-203.

Kerr, M. M., \& Zigmond, N. (1986). What do high school teachers want? A study of expectations and standards. Education and Treatment of Children, 9, 239-249.

Kleinbaum, D. G., Kupper, L. L., Muller, K. E., \& Nizam, A. (1998). Applied regression analysis and other multivariate methods (3rd ed.). Boston: PWS-Kent.

Landrum, T., J., Tankersley, M., \& Kauffman, J. M. (2003). What is special about special education for students with emotional or behavioral disorders? The Journal of Special Education, 37, 148-156.

Lane, K. L. (1999). Young students at risk for antisocial behavior: The utility of academic and social skills interventions. Journal of Emotional and Behavioral Disorders, 7, 211-223.

Lane, K. L. (2004). Academic instruction and tutoring interventions for students with emotional/behavioral disorders: 1990 to present. In R. B. Rutherford, M. M. Quinn, \& S. R. Mathur (Eds), Handbook of research in emotional and behavioral disorders (pp. 462-486). New York: Guilford Press.

Lane, K. L., Carter, E. W. Pierson, M. R., \& Glaeser, B. C. (2006). Academic, social, and behavioral characteristics of high school students with emotional disturbances and learning disabilities. Journal of Emotional and Behavioral Disorders, 14, 108-117.

Lane, K. L., Givner, C. C., \& Pierson, M. R. (2004). Teacher expectations of student behavior: Social skills necessary for success in elementary school classrooms. Journal of Special Education, 38, 104-110.

Lane, K. L., Gresham, F. M., MacMillan, D., \& Bocian, K. (2001). Early detection of students with antisocial behavior and hyperactivity problems. Education and Treatment of Children, 24, 294-308.

Lane, K. L., Gresham, F. M., \& O'Shaughnessy, T. E. (2002). Identifying, assessing, and intervening with children with or at risk for behavior disorders: A look to the future. In K. L. Lane, F. M. Gresham, \& T. E. O'Shaughnessy (Eds), Interventions for children with or at risk for emotional and behavioral disorders (pp. 317-326). Boston: Allyn \& Bacon.

Lane, K. L., Pierson, M., \& Givner, C. C. (2004). Secondary teachers' views on social competence: Skills essential for success. Journal of Special Education, 38, 174-186.

Lane, K. L., Wehby, J. H., \& Cooley, C. (2006). Teacher expectations of student's classroom behavior across the grade span: Which social skills are necessary for success? Exceptional Children, 72, 153-167.

Lane, K. L., Wehby, J. H., Little, M. A., \& Cooley, C. (2005a). Academic, social, and behavioral profiles of students with emotional and behavioral disorders educated in self-contained classrooms and self-contained schools: Part I-are they more alike than different? Behavior Disorders, 30, 349-361.

Lane, K. L., Wehby, J. H., Little, M. A., \& Cooley, C. (2005b). Students educated in self-contained classes and self-contained schools: Part II - How do they progress over time? Behavior Disorders, 30, 363-374.

Lane, K. L., Wehby, J. H., Phillips, A., Weisenbach, J., Little, M. A, \& Merwin, M. (2007). The utility of academic and behavioral interventions for early elementary students with reading and behavior problems. Manuscript in preparation.

Lipsey, M. W., \& Wilson, D. B. (2001). The way in which intervention studies have "personality" and why it is important to meta-analysis. Evaluation and the Health Professions, 24, 236-254.

Mattison, R. E., Hooper, S. R., \& Glassberg, L. A. (2002). Three-year course of learning disorders in special education students classified as behavioral disorder. Journal of the American Academy of Child \& Adolescent Psychiatry, 41, 1454-1461.

Mattison, R. E., Spitznagel, E. L., \& Felix, B. C. (1998). Enrollment predictors of the special education outcome for students with SED. Behavioral Disorders, 23, 243-256. 
Meadows, N. B., Neel, R. S., Scott, C. M., \& Parker, G. (1994). Academic performance, social competence, and mainstream accommodations: A look at mainstreamed and nonmainstreamed students with serious behavioral disorders. Behavioral Disorders, 19, 170-189.

Mooney, P., Epstein, M. H., Reid, \& Nelson, J. R. (2003). Status of and trends in academic intervention in research for students with emotional disturbance. Remedial and Special Education, 24, 273-287.

Nelson, J. R., Babyak, A., Gonzalez, J., E., \& Benner, G. H. (2003). An investigation of the characteristics of K-12 students with comorbid emotional disturbance and significant language deficits served in public schools. Behavioral Disorders, 29, 25-33.

Nelson, J. R., Benner, G. J., Lane, K., \& Smith, B. W. (2004). An investigation of the academic achievement of K-12 students with emotional and behavioral disorders in public school settings. Exceptional Children, 71, 59-73.

Reid, R., Gonzalez, J., Nordness, P. D., Trout, A., \& Epstein, M. H. (2004). A meta-analysis of the academic status of students with emotional/ behavioral disturbance. The Journal of Special Education, 38, 130-143.

Singer, J. D., Butler, J. A., Palfrey, J. S., \& Walker, D. K. (1986). Characteristics of special education placements: Findings from probability samples in five metropolitan school districts. The Journal of Special Education, 20, 319-337.

Sutherland, K. S., \& Wehby, J. H. (2001). The effects of self-evaluation on teaching behaviors in classrooms for students with emotional and behavioral disorders. Journal of Special Education, 35, 161-171.

Trout, A. L., Nordness, P. D., Pierce, C. D., \& Epstein, M. H. (2003). Research on the academic status of children with emotional and behavioral disorders: A review of the literature from 1961 to 2000. Journal of Emotional and Behavioral Disorders, 11, 198-210.

Wagner, M., \& Cameto, R. (2004). The characteristics, experiences, and outcomes of youth with emotional disturbances. NLTS2 Data Brief, 3(2).

Walker, H. M., Block-Pedago, A., Todis, B., \& Severson, H. (1991). School archival records search. Longmont, CO: Sopris West.

Walker, H. M., Irvin, L. K., Noell, J., \& Singer, G. H. S. (1992). A construct score approach to the assessment of social competence: Rationale, technological considerations, and anticipated outcomes. Behavior Modification, 16, 448-474.

Walker, H. M., \& McConnell, S. (1995). The Walker-McConnell scale of social competence and school adjustment-elementary version. Technical manual. San Diego, CA: Singular.

Walker, H. M., Ramsey, E., \& Gresham, F. M. (2004). Antisocial behavior in school: Evidencebased practices (2nd ed.). Belmont, CA: Wadsworth.

Walker, H. M., \& Rankin, R. (1983). Assessing the behavioral expectations and demands o less restrictive setting. School Psychology Review, 1, 274-284.

Walker, H. M., \& Severson, H. H. (2002). Developmental prevention of at-risk outcomes for vulnerable antisocial children and youth. In K. L. Lane, F. M. Gresham, \& T. E. O'Shaughnessy (Eds.), Interventions for children with or at risk for emotional and behavioral disorders (pp. 177-194). Boston, MA: Allyn \& Bacon.

Wechsler, D. (1991). Wechsler intelligence scale for children - Third Edition. San Antonio, TX: Harcourt Brace Jovanovich, Inc.

Wehby, J. H., Falk, K. B., Barton-Arwood, S., Lane, K. L., \& Cooley, C. (2003). Impact of comprehensive reading instruction on the academic and social behavior of students with emotional and behavioral disorders. Journal of Emotional and Behavioral Disorders, $11,225-238$.

Wehby, J. H., Lane, K. L., \& Falk, K. B. (2003). Academic instruction for students with emotional and behavioral disorders. Journal of Emotional and Behavioral Disorders, 4, 194-197.

Woodcock, R. W., McGrew, K. S., \& Mather, N. (2001). Woodcock-Johnson III Tests of Achievement. Itasca, IL: Riverside Publishing. 